\title{
Model of Value Based Innovation
}

\author{
Manuel Teles Fernandes \\ CAAM (Corporate Academy for Advanced Management)/Gestão Total, Lda., Samora Correia, Portugal \\ José Moleiro Martins \\ ISCAL (Instituto Superior de Contabilidade e Administração de Lisboa), Lisboa, Portugal
}

\begin{abstract}
The paper presents to managers' and scholars' reasons for using models to determine the strategic importance of innovation and its potential value creation. The model of value based innovation (VBI) provides a clear definition of the adequate value curve to be pursued in any innovation action, from strategic definition to operational product conceptualization and production. The VBI model has been applied in strategic planning in over 100 SMEs throughout Portugal and USA by the authors and other consultant companies. The VBI model provides the practitioners and scholars with a pragmatic tool to determine innovation's value creation. Connecting this information with strategic thinking and planning will reduce risk and avoid failure. The theoretical model when converted into a technological application provides an immediate insight into the most adequate strategic innovation to be chosen by top management and operational product developers. The paper demonstrates the relation between innovation and value creation.
\end{abstract}

Keywords: business model, innovation, value creation

\section{Introduction}

Many academics and professional practitioners have worked on visual and non-visual models trying to represent innovation in its different dimensions (Abernathy \& Clark, 1985; Christensen, 1997; Davila, Epstein, \& Shelton, 2006; Kelly \& Littman, 2006; Kingsland, 2007; Kline \& Rosenberg, 1986; Markides \& Geroski, 2005; Sawhney, Wolcott, \& Arroniz, 2006; Shumpeter, 1942). Their attempts have brought a better understanding to the market about how innovation evolves, develops, disseminates and transforms the economy. However, the conceptual format of many of those models makes their operational application difficult for firms. Entrepreneurs as well as strategy and innovation managers and practitioners have been seeking for a long time for a model that can, in a simple and clear fashion, indicate the most appropriate kind of innovation to be developed and applied in their businesses.

The purpose of this paper is to present top management and scholars with a practical innovation model, which brings the decision to a simple and unique proposition solving entrepreneurs' and managers' doubts and

\footnotetext{
Manuel Teles Fernandes, MBA, CEO of the Corporate Academy for Advanced Management/Gestão Total Lda.. José Moleiro Martins, Ph.D., Adjunct Professor, Management Division, ISCAL (Instituto Superior de Contabilidade e Administração de Lisboa).

Correspondence concerning this article should be addressed to Manuel Teles Fernandes, Av. Prof. Egas Moniz, Parque do Alto E3-E4, 2135-232 Samora Correia, Portugal. E-mail: manuel@telesfernandes.net; mtf@gestaototal.com.
} 
highlights the strategic reasons to use innovation as a means to increase value creation.

The paper is organized as follows. The literature is reviewed in section two. Section three analyzes the model of value based innovation (VBI) which provides practitioners and scholars with a pragmatic tool to determine the value creation of innovation. Finally, section four concludes the paper.

\section{Literature Review}

As an attempt to comprehend innovation, many authors have come up with their own understanding of such phenomenon. Schumpeter (1942) defines technological changes and advances as the great cause of economical and industrial changing. To him, the economical cycles in capitalism are the result of changes imposed by innovation, which takes on two aspects: The introduction of revolutionary products and services by successful entrepreneurs are fundamental for the sustainable growth of the economy in the long term, but, on the other hand, it also destroys, in the short term, the power of the established ones. Those fundaments transform innovation into a destructive action. Schumpeter divides the process of change in three major steps: invention, innovation, and diffusion. Abernathy and Clark (1985) define innovation as the initial introduction to the market of a new product, a conceptualization which is radically different from previous practices. They have suggested four archetypes for innovation: niche creation, regular innovation, revolutionary innovation, and architectural innovation. Cummings (1998) refers to innovation as the first well succeeded application of a product or process. However, the concept of well succeeded application keeps any attempt that fails to reach the market out of the innovation arena. Piana (2003) refers to innovation as the activity of people and organizations aimed at introducing changes to them or to the environment. Innovation can also be, according to this author, an individual attitude, an organizational process and a social movement. Therefore, innovation can be applied to products, processes and behaviours. Tidd (2006) refers to innovation as the attempt to work at the frontier level of technology, fragmenting market movements throughout the globe, and at the level of political uncertainty, regulation instability and new competitors coming from many different directions. To be successful in this environment, one has to be very good in managing innovation at the network level. Tidd opens a new window in which context and environment are also susceptible of innovation. Now, after having been from inside out and outside in, innovation can be also from inside.

The innovation must have a degree of novelty (OECD, 2005). Three concepts of novelty or innovation are mentioned: new to the firm, new to the market, and new to the world. A related concept is a radical or disruptive innovation. It can be defined as an innovation that has a significant impact on a market and on the economic activity of firms in that market. This concept focuses on the impact of innovations as opposed to their novelty. The impact can, for example, change the structure of the market, create new markets or render existing products obsolete (Christensen, 1997). However, it might not be apparent whether an innovation is disruptive until long after it has been introduced.

Kingsland (2007) proposes that innovation can be applied at five different levels: product, service, process, business model, and organizational structure. He suggests three types of innovation: breakthrough, differential, and incremental. This approach introduces the word differential into the used lexicon, meaning that innovation can be applied to create differentiation in new products, processes or markets.

Many authors refer to differentiation as vertical when it creates a new or different value for consumers, 
related to the quality offered, and horizontal when it creates a different price for consumers, which is related to the offered variety of the product This concept is used mainly at the macro-economical level, mostly to understand intra-industry trade among countries, but the same concept can be used by firms to comprehend the practical implications it can have on their innovative actions.

The pioneering models of Krugman $(1979,1980)$ and Lancaster $(1980)$ take the horizontal differentiation view, and Falvey (1981), Falvey and Kierzkowski (1984) and Flam and Helpman (1987) introduced the vertical differentiation on products. Companies differentiate their products to avoid competition. Doing so, they justify different prices. The vertical differentiation takes quality as the basic distinction. However, horizontal differentiation reflects formally the Hotelling competition format (Hotelling, 1929), transforming the price differentiation into a ruinous proposition for some competitors. The product differentiation provides firms with the possibility of recovering some power in the market. Anderson (2005) mentions that this situation allows corporations to overcome the Bertrand paradox, which would imply that the price of all competitors would be homogenous. The market logic, according to Bertrand's competition concept, forces corporations to bring their prices to the marginal cost level, the unique possible equilibrium point-equilibrium of Nash (1950). Anderson mentions that, based on special attributes which can differentiate a product from direct competitors, enterprises can exercise some pressure on the market establishing their prices without having an elastic answer from consumers, meaning that a differentiated product becomes a variable of choice, avoiding the Bertrand paradox. Narajabad and Watson (2007) refer that a less expensive horizontal differentiation depends on the consumers' preference for heterogeneity and that innovation increases, if that preference is high, and that innovation diminishes, if the same preference is low. Manez and Waterson (2001) conclude that at the vertical differentiation level three interrelated results can be identified: (1) the self-price elasticity diminishes when the product quality increases; (2) the cross product price elasticity diminishes when overall quality increases; and (3) the product profit margin increases with the increment in quality.

Many innovation models (Abernathy \& Clark, 1985; Davila et al., 2006; Markides \& Geroski, 2005; Schumpeter, 1942) are set on what Kline and Rosenberg (1986) call the linear innovation model, where research, development, production and commercialization follow an order and sequential process. However, many other innovation models (Christensen, 1997; Kusiak \& Tang 2006; Sawhney et al., 2006) are set upon what Kline and Rosenberg named the interactive model of innovation.

In the next section, we present the model of VBI which has been applied in strategic planning in over 100 small and medium enterprises (SMEs) throughout Portugal and the USA by the authors and others consultant companies.

\section{Value Based Innovation}

The VBI model proposed in this paper brings all previous understandings of innovation to the organizations' operational level, in a very practical and easy understand way, allowing innovation managers and practitioners to define the most appropriate type and scope of innovation to be developed and implemented.

\section{Sustainable Innovation Products}

In today's economy, it is frequent to hear academics, managers and entrepreneurs say that innovation is the key for success in any business. From simple and basic innovation to complex and broad innovation, everyone 
says that we need to innovate products, services and processes. Big organizations invest large percentages of their overall turnovers into research and development of new products and working processes, trying to be ahead of competitors by introducing new concepts into the market and conquering new consumers.

There are many different theoretical concepts of innovation, developed along the years by academics, managers and researchers. The conceptual idea is based on the fact that every product improves its own performance along the time dimension (life cycle) until a stage, when its performance is so high, full of unnecessary functionalities, and so costly that a large part of the market has no desire to acquire the product. It is at that point in time that someone with a cheaper product proposition, even with lower performance or less functionalities, will take the non-served part of the market, creating a disruptive movement.

In order to be disruptive, and adopting some of Christensen's principles, there are some fundamental ideas that should be considered. These are: (1) A product is disruptive when, through new and cheaper technology, even with less functionalities, it responds to the basic consumer's needs with a much lower price (cost to consumer); (2) Despite the fact that the product may have less functionalities, the same product covers the existing basic needs of a large number of consumers, many of them sitting at the bottom of the consumer pyramid, who could not buy the existing products because they were not able to afford the demanded price. It also covers the needs of some consumers existing at the middle of the pyramid who prefer to lose some functionalities, but purchase the new product at a much lower price; (3) The disruptive product sells at a much lower price, but it also costs much less due to the new and more productive technology used, giving the producer a higher profit margin; (4) A disruptive product has to be unique, difficult to be copied by competitors and impossible to be substituted in its application by any other with the same functionalities, performance, and price.

The concept of disruptive innovation has created a new vision on the market place, not because it supports the idea of creating completely new products, which may not be true all the time, but because it supports the idea of targeting a much wider range of potential consumers, as shown in Figure 1. Considering that the consumer pyramid can adopt even flatter conditions, depending on the kind of product, the base shows a great potential market growth, if the price is aligned with the consumers' purchasing power. However, a truly disruptive product serves not only the base of the pyramid but also the middle section. This provides any real disruptive product with a greater chance of success. There are always consumers at the top of the pyramid looking for more complex solutions and higher performance products, who will never adopt the disruptive product, unless the previous one disappears from the market.

But this raises a new question: How do products align?

Considering the concept of sustainable innovation, which is very much the continuous improvement process of products and working processes, we may find that the ascendant line representing the progress of a product on the model may not represent the full range of varieties or segmentations that the same product may have been exposed to. By segmenting the market, marketers create differentiated products to serve different market segments. More segmentation means more differentiated products, and at a certain point in time, we may find that a certain product possesses different identities (i.e., dimensions). The car industry is one of the most segmented industries, providing a wide variety of always the same product: the automobile. Among the wide variety of different automobiles we can find the basic commodity car and the top premium car. It is as if the product was living in some different and parallel dimensions at the same time, as shown in Figure 2. 


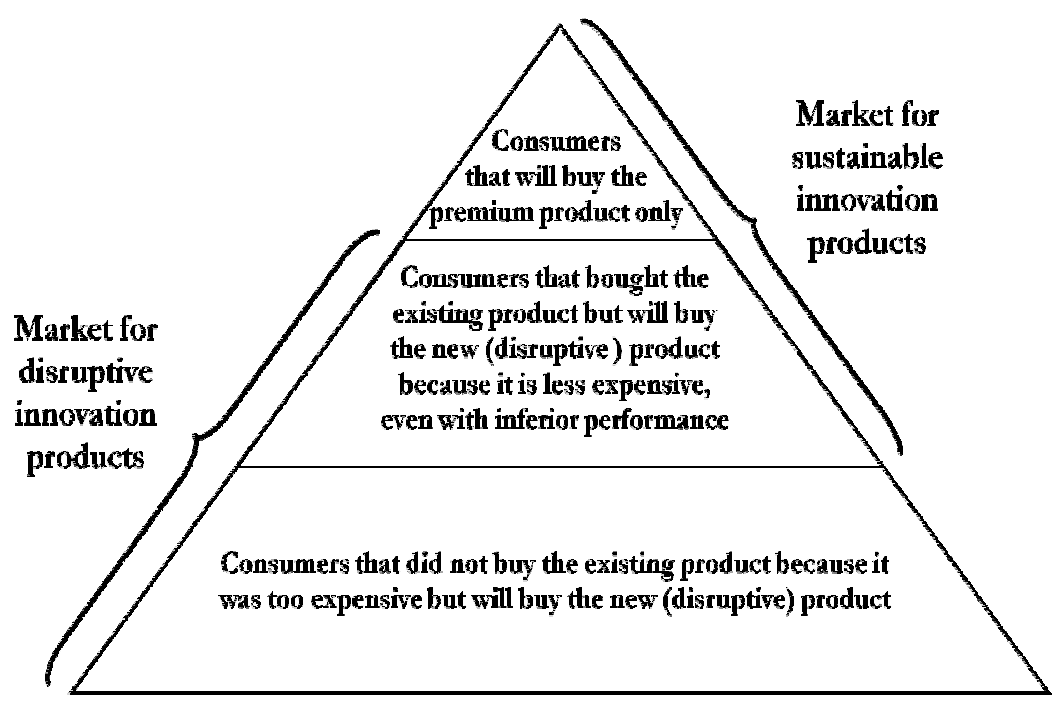

Figure 1. Consumer pyramid and preferred products.

Differentiation has, then, created a number of different varieties of the same product. These varieties live in different value levels and market environments. The commodity product has a low organizational effort in innovation and differentiation, and serves a market environment with low potential growth and many competitors. On the opposite side, the premium product serves a market niche with a higher potential growth and a much lower number of competitors or none, but the producer must develop a great effort to innovate and differentiate the product.

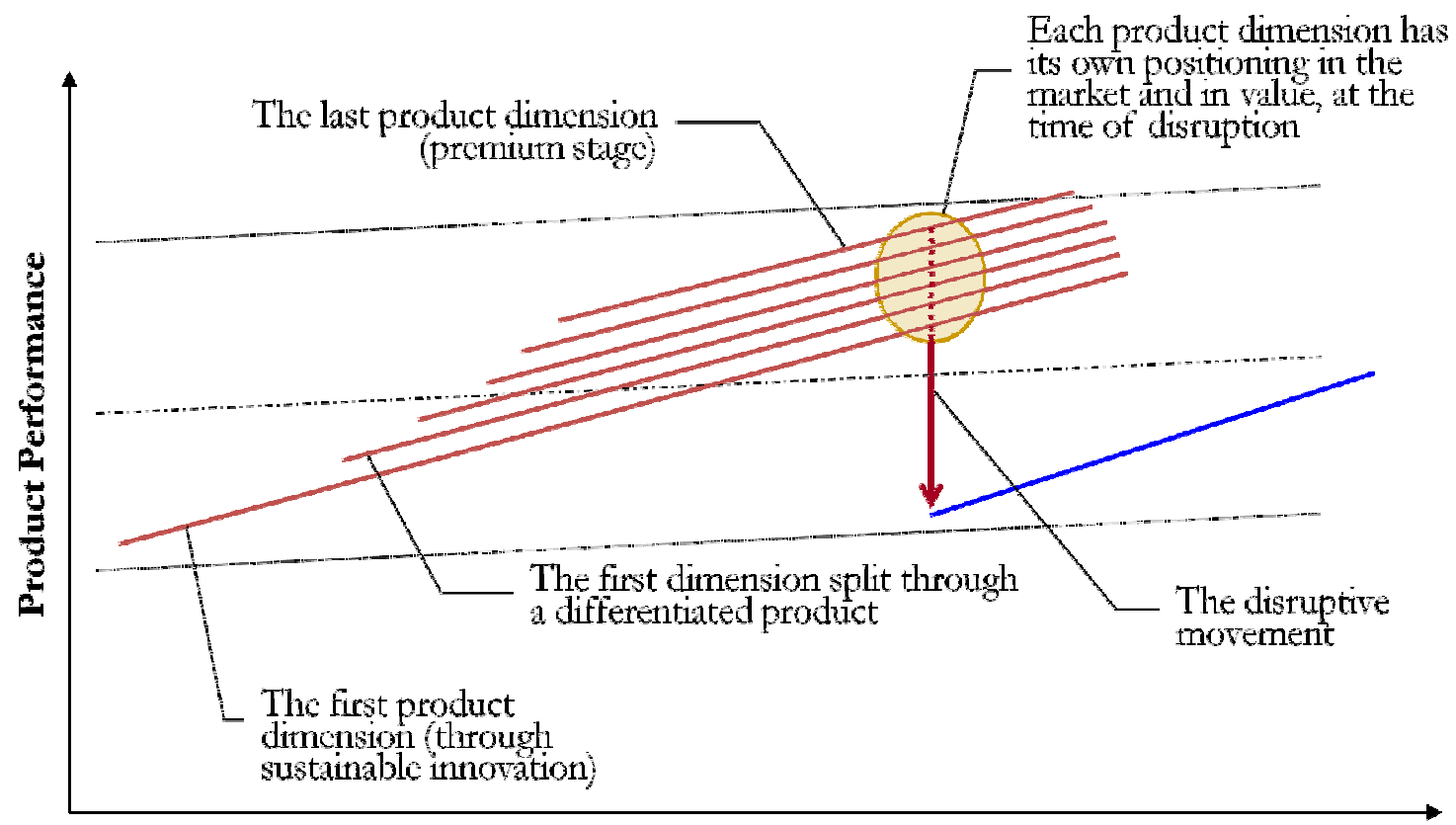

\section{Time}

Figure 2. Parallel dimensions of sustainable innovation.

At this point, we are able to say that, from the model in Figure 2, we can identify four different innovation moments during the product's life cycle: (1) the initial innovation that has created the product in the first instance; 
(2) the sustainable innovation corresponding to the continuous improvement of the product; (3) the creation of different qualitative levels, including the premium level; and (4) the creation of a new alternative product for many consumers through the disruption movement. Later, we will use those four moments in our proposal for a new innovation model.

Leaving aside all other important factors that will make the product succeed in the market, we shall focus on the value of the product to determine the impact of innovation.

Consumers determine the value of any product, when they decide to buy or not to buy it. In their appreciation of the product value, consumers consider two major variables: levels of performance (attributes and functionalities) and price (cost to acquire). The performance level derives from the functionalities the product can deliver, being intrinsic, if serving the purpose for which the product has been conceived or extrinsic, if providing extra benefits like prestige or some functions that no other similar product can deliver. The price level has to do with what the consumers think is appropriate or with what producer or vendor imposes on the market. The concept of value has been used broadly, but the one we need to use in this paper is the one that has to do with value management. This takes into consideration the direct relation between the given satisfaction of consumer needs provided by the functionalities of a product, and the resources used to acquire the product, being money or any other.

However, when evaluating a product in a decision-making situation, consumers look at products in a different way. Functions and price are all considered as the product's attributes. They see these attributes in terms of qualitative or quantitative performance, scoring each one of them in a very own and personal scale. That should be also the method that companies must use to appraise the performance of their products' attributes, creating a value curve for their products that can also be compared with their competitors' performances.

\section{Insights for Business}

In the business world, innovation is often not something one can plan and predict in detail beforehand. It is, mainly and most times, the result of occasional discoveries, through an experimental action process of trial and error, that brings new products and services into the world that we all ought to have.

In order to understand what innovation is and how it happens, we should look into the present and back into the past and analyze lived experiences, through empirical observation. This will help us to find when and why for innovation to occur.

The reasons behind the emergence of innovation can be divided in three groups: (1) new consumer needs: functional (new functions that consumers demand), operational (need to make utilization by consumers easier), and design (need for fashion alternatives for consumers); (2) new market contexts: business environment (new political, economical and social demands), rivalry (changes in type and number of competitors), and environmental (scarcity of natural resources); and (3) new capabilities of the industry: new knowledge (scientific and technological), applied technology (at the hardware and software levels), and inputs (new materials).

Innovation can occur at two different levels: (1) at the product level: functions, inputs (materials), and design (product and packaging); (2) at the organizational level: productive processes (equipments and materials), management (organizational structure, information and communication technology and institutional relations), and marketing (promotion and distribution). 
To create a product or service, i.e., to make it appear in the market via some kind of innovation process, we need to analyze it through two different organization's standing points: (1) the external view or the degree of difficulty that will be faced in satisfying all the demands from the market, which have to be overcome in order to create or develop the expected response to consumers; and (2) the internal view or the degree of effort of organizational capability needed or applied during the innovation process in order to achieve the expected final result.

These two major factors are the baseline for innovation and they determine the kind of innovation which organizations implement in their search for their product value positioning.

Difficulty in satisfying the market. The higher or lower degree of difficulty in satisfying the given demands placed by the market that an organization has to overcome results from two factors: (1) the external context of forces that have created the need or requests for the innovation; and (2) the level of quality demanded by consumers for the final solution.

The context of forces can be classified as existing or new: Existing contexts demand solutions in alignment with what existed before and new contexts demand new and unpredictable solutions. The transportation of people by airplane can be considered as an existing context, since it has been stabilized for many years. The future transportation of passengers into space, however, will create a new context for the manufacturers of spaceships. The forces come from the following factors: economical, functional, social, political, and environmental. Each of these five factors must be analyzed, classified and combined with all other factors to determine the position where we are in the context forces.

The level of qualitative demands can be classified as low or high. Low quality demands are easier to satisfy and will not require special product and service attributes to be at top performance. High qualitative level demands represent a greater difficulty to arrive at the demanded satisfaction, as the quality requirements will be more in quantity and higher in quality. This is a very dynamic condition, and it can change without warning from the market. The level of quality required for innovations in the shoes industry and in the medical equipment industry is quite opposite. However, some products in those industries may demand levels of quality in innovation far from the average of the rest of the industry, and that may even change with time, location, consumers and so on. The quality demanded is determined by the following factors: functionality (needed functions), operational usage (utilization), design (prestige and esteem), reliability, and availability. We must determine and classify each of these five factors and combine the final results to provide the positioning at the quality level demanded by the market.

Applied capability in the innovation process. The higher or lower degree of needed or applied capability in the innovation process also derives from two factors: (1) the level of scientific knowledge and competences; and (2) the level of technological capability to create solutions.

The applied scientific knowledge and competences during the innovation process can be classified into two levels: existing or to be created. In most cases, organizations use the existing scientific knowledge and competences to arrive at the needed solutions. In some few cases, organizations need to create and develop new scientific knowledge and competences in order to achieve the required solution. The need to develop the technology for nuclear fusion is forcing scientists to create new scientific knowledge and competences. Making cars using bio-fuel is achieved with existing scientific knowledge and competences, despite the fact that it may mean two completely different engine technologies. Scientific knowledge results from the following factors: 
research and development (R\&D), functional management, competences and experience, creativity and design, and market and consumer knowledge.

The level of the technological capability to create solutions can also be classified as existing or as to be created. Most examples of innovation are using the existing capability to create solutions, that is, they use existing means to perform a certain functional need. An electric vehicle needs a new technological solution to make use of lithium-ion batteries instead of fossil fuel with the same results, but it will also need existing technological solutions to control the power and speed of the engine, even if this has different characteristics. The technological capability derives from R\&D, production equipment, information systems, materials, and processes. These factors are used in the value creation through the four innovation archetypes.

Innovation archetypes for value creation. The degree of difficulty in satisfying the identified requests and the degree of organizational capability needed or applied in the innovation process can now be combined, resulting in four archetypes of innovation: (1) breakthrough; (2) turning-around; (3) adding-value; and (4) up-grading.

The breakthrough innovation means that the final solution is a new unique product, answering new needs and delivering new functions. Every existing product was once first introduced into the market as a result of something new. The telephone, the radio and the television were all in the first instance real breakthroughs. The breakthrough innovation happens many times by serendipity or mistake. The $x$-ray was the result of the discovery of the radiation properties of uranium, by the Currie couple. That was the trigger to make use of such condition in new applications. Something that was unthinkable could then become a reality.

The turning-around innovation is applied in the creation of an alternative product to replace an existing one, but with less functionalities or performance, at a much lower price, covering the basic needs on the base of the consumers pyramid. In order to produce a new product with less functionalities and lower performance, but at a much lower price for consumers, some kind of new technology or other capabilities is needed, which will make such realization viable. This is similar to Christensen's disruptive innovation.

The adding-value innovation is applied in the development of new functionalities and in the increment of performance of all attributes in an existing product, responding to specific needs of a market segment and creating a new dimension of the existing product. Often this corresponds to the premium versions of a product, like in the case of cars and watches.

Finally, the up-grading innovation is applied to differentiate an existing mature product, still serving the same market segment, but pushing up on the satisfaction of consumers' needs. Up-grades on some commodities or services are normally small innovations that try to differentiate the product from competitors, achieving such result for a short limited time only, while competitors do not react. This corresponds to the simple and incremental innovation, also named sustainable innovation by Christensen.

Next, we will see the relation between innovation and value creation.

Aligning value and innovation. To understand value, as defined in value management, we need to consider two major variables: functionalities (representing satisfaction of requests), and price (representing utilized resources).

To determine the positioning on the functionalities axis, we need to analyze five factors: performed functions, design and image, characteristics, needs served, and brand. 
To determine the positioning on the price axis, we need to analyze other five factors: price elasticity, purchasing options, knowledge of needs versus product, product utilization, and negotiating power.

Constructing a matrix out of those two major variables, and taking in consideration their specific factors, we can determine four different archetypes for value, as in Figure 3. These archetypes are: (1) commodity: products of low value, at low price, serving basic functions, in advance or late stage of maturity; (2) best-value: products with extrinsic functions, even if only for the base of the consumers pyramid, at accessible price; (3) premium: products with strong extrinsic functions, serving a market niche at the top of the consumers pyramid, at a high price; and (4) lesser-value: products that consumers consider only with basic functionalities sold at a high price and, therefore, not adopted by the market.

When aligning these four archetypes of value with the ones of innovation, as shown in Figure 3, we conclude that each type of innovation creates a specific level of value.

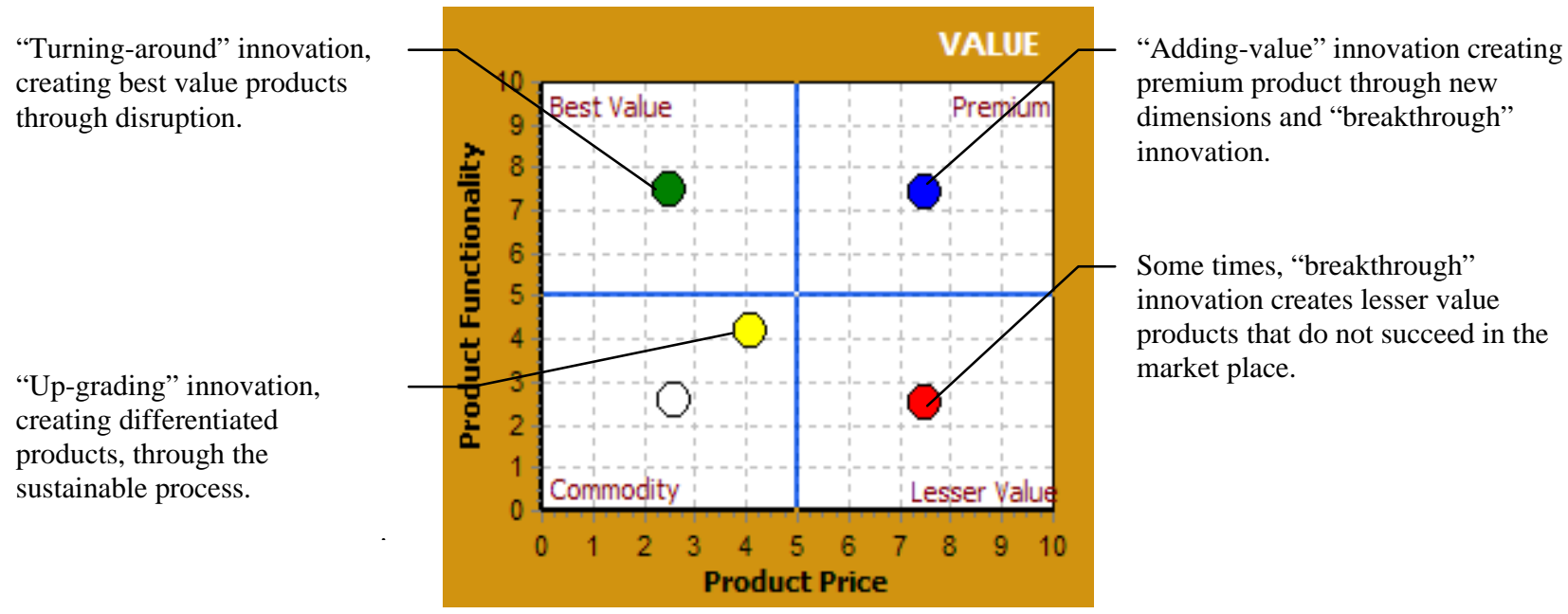

Figure 3. Innovation and value alignment.

The breakthrough innovation can, hypothetically, position the product in any of the four quadrants. However, as this kind of product results from some new developed technology and competence, in which someone has invested a great deal, it may be high priced, at the price level imposed by the supplier. Therefore, the product must be either in the premium or in the lesser value quadrants. In case of low costs in the development phase, it may happen that the supplier will position the product in the best value quadrant, situation only found very rarely and occasionally. The future nuclear fusion electrical central power plants will emerge due to a breakthrough innovation.

The turning-around innovation takes the product inevitably onto the best value quadrant. Due to the fact that the simplification of a product means less functionalities and/or lower performance, but at a much lower acquisition price for the consumer as a result of the utilization of new technology that allows costs to be also heavily reduced, it will surface in the market as the awaited possibility for a large number of consumers at the bottom of the consumers pyramid, providing the desired performance at a low price. The turning-around innovation is very much what Christensen has named as disruptive innovation. The second generation of mobile phones came in the market due to a disruptive innovation, when it become possible to have a cheaper product, even with a not so good performance as the first generation mobile phones, but at a price that almost everyone 
could afford.

The adding-value innovation corresponds to the innovation that many manufacturers in the industrial field or other organizations in the service field apply to the product or the service in order to adjust it to the specific needs of some market segment and niche. Normally, they add more functionalities to the product, higher performance in qualitative and quantitative terms, and create a brand name that means exclusivity, prestige, style and so on. This kind of innovation adds new dimensions to products, separating the commodity from the premium and having, sometimes, many middle dimensions. This applies to products that have become a commodity, positioned at the last stage of their life cycles, when a producer develops high efforts to differentiate a variance of the product from the remaining competitors. This is also a last resource to obtain a higher margin on something that, due to its condition of commodity, suffers high pressure from consumers and competitors at the price level. Well-succeeded adding-value innovation strategies may take products to the premium archetype for long periods of time. The very expensive watches targeting the very high classes emerge as a result of adding-value innovation strategies.

The up-grading innovation applies to any situation where the supplier tries to innovate through a differentiation process. It shows up as the result of giving higher performance to some attributes of the product in comparison with other competing products. The product may still be a commodity, but it is seen by consumers as possessing higher value and, therefore, appeals to those with more purchasing capacity. The effort the car industry has put in to create the SUV car dimension illustrates this concept.

The model provides practitioners and scholars with a pragmatic tool to determine the value creation of innovations. Combining this information with strategic thinking and planning will reduce risk and avoid failure.

\section{Conclusion}

In business, we can introduce changes and create some kind of impact only in two areas: product value and organization's effort. The value can be changed, if the attributes of the product are redefined in order to make its value curve stand out from the competition. Innovation plays a great part in this process of changing the product value.

Changing the value of the product, according to consumer needs and preferences, will have an impact on product margin and, consequently, on potential profit and adequate strategy. Any changes of effort and adjustments must follow value changes, keeping both in alignment with each other in order to maintain the desirable product margin. Changes on the value side can also discover or create new markets, which will have an impact on the potential profit and strategy as well. The changes on the organization's effort side must be performed at the level of the organizational structure, intervening in the areas of authority and responsibility, learning and competences, processes and technologies.

The models presented in this paper must be used as integrated tools, providing an overall and integrated view of any potential business proposition, which will help managers to make decisions in relation to their future course of action. For that purpose, a technological application (software) has been developed, which provides an immediate insight into the most adequate strategic innovation to be chosen by top management and operational product developers.

The VBI model will provide practitioners and scholars with a pragmatic tool to determine the value creation 
of innovation. Combining this information with strategic thinking and planning will reduce risk and avoid failure.

The purpose of this paper is to demonstrate the relation between innovation and value creation.

The presented VBI model links innovation and its archetypes to value creation, determining the adequate value curve for each archetype and also identifying the most appropriate value positioning for those archetypes, which connects to the strategic definition and planning.

\section{References}

Abernathy, W., \& Clark, K. (1985). Innovation: Mapping the winds of creative destruction. Research Policy, 14(1), 3-22.

Anderson, S. (2005). Product differentiation. New Palgrave Dictionary contribution, University of Virginia, Charlottesville.

Christensen, C. (1997). The innovator's dilemma. New York: Harper Business.

Cummings, B. (1998). Innovation overview and future challenges. European Journal of Innovation Management, 1(1), 21-29.

Davila, A., Epstein, M., \& Shelton, R. (2006). Making innovation work. Wharton School Publishing, Upper Saddle River, NJ.

Falvey, R. (1981). Commercial policy and intra-industry trade. Journal of International Economics, 11(4), 495-511.

Falvey, R., \& Kierzkowski, H. (1984). Product quality, intra-industry trade and (im)perfect competition. Discussion paper, Graduate Institute of International Studies, Geneva.

Flam, H., \& Helpman, E. (1987). Vertical product differentiation and North-South trade. American Economic Review, 77(5), 810-822.

Hotelling, H. (1929). Stability in competition. Economic Journal, 39(153), 41-57.

Kelly, T., \& Littman, J. (2006). The ten faces of innovation: IDEO's strategies for beating the devil's advocate and driving creativity throughout your organization. New York: Doubleday Publishers.

Kingsland, B. (2007). Proposal for new innovation measurement, U.S. Department of Commerce. Economics and Statistics Administration, May 07.

Kline, S., \& Rosenberg, N. (1986). An overview of innovation. In R. Landau, \& N. Rosenberg (Eds), The positive sum strategy: Harnessing technology for economic growth. Washington, D.C.: National Academy Press.

Krugman, P. (1979). Increasing returns, monopolistic competition, and international trade. Journal of International Economics, 9(4), 469-480.

Krugman, P. (1980). Scale economies, product differentiation, and the pattern of trade. American Economic Review, 70(5), 950-59.

Kusiak, A., \& Tang, C. (2006). Data-inspired innovation model. Proceedings of the 36th International Computers and Industrial Engineering Conference, June 2006, Taipei, Taiwan.

Lancaster, K. (1980). Intra-industry trade under perfect monopolistic competition. Journal of International Economics, 10(2), 151-170.

Manez, J., \& Waterson, M. (2001). Multiproduct firms and product differentiation: A survey. Warwick economic research papers No. 594, Department of Economics, University of Warwick.

Markides, C., \& Geroski, P. (2005). Fast second. John Wiley \& Sons, Chichester.

Narajabad, B., \& Watson, R. (2007). A dynamic duopoly with endogenous horizontal and vertical differentiation. Working paper, Department of Economics University of Texas, Austin.

Nash, J. (1950). Equilibrium points in n-person games. Proceedings of the National Academy of Sciences, 36(1), 48-49.

OECD. (2005). Oslo manual: Guidelines for collecting and interpreting innovation data (3rd ed.).

Piana, V. (2003). Innovation. Retrieved from http://www.economicswebinstitute.org

Sawhney, M., Wolcott, R., \& Arroniz, I. (2006). The twelve different ways for companies to innovate. Sloan Management Review, 47(3), 75-81.

Schumpeter, J. (1942). Capitalism, socialism and democracy. London: Unwin.

Tidd, J. (2006). Innovation models. Discussion paper No. 1, Science and Technology Policy Research Unit, Imperial College London, Tanaka Business School, University of Sussex. 